See Article page 37

\section{Commentary: Support for the right}

Luigi Lagazzi, MD, Fatima Asad, BS, Ashley Gall, BS, and J. W. Awori Hayanga, MD, MPH

This timely and relevant contribution delineates technical advice in the implantation of right ventricular support devices. ${ }^{1}$ The mitigation of right ventricular dysfunction is of great import because right ventricular dysfunction is the Achilles' heel of many pathophysiological processes that affect the left ventricle. As such, these are tips for contemporary practice. The technical tip of augmentation using felt bolsters for the inflow cannula is of particular value and is likely to be well received. Nevertheless, the recommendation of an outflow graft anastomosed at $90^{\circ}$ to the pulmonary artery may be somewhat contentious. Indeed, some might argue that a more acute angle would be less susceptible to turbulence and compression. In addition, although not explicitly stated, the implantation in this case necessarily pertains to long-term right ventricular support instead of short-term support using temporary devices that often overlap with extracorporeal support.

The value of transesophageal echocardiography cannot be overstated, although the authors expressed reliance on making an imprint at the side of the cannula using an index finger pressed on the right atrium This act may not necessarily always be achievable because of the anatomy and small size of the right atrium. The discussion regarding

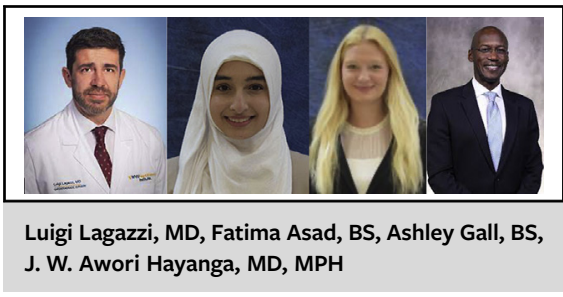

CENTRAL MESSAGE

Supporting the right ventricle is a

growing concern in mechanical

circulatory support.

potential thrombosis and the prophylactic measures that could be deployed in the context of such thrombosis is also worthy of mention. The thrombosis in this regard is typically not in situ thrombosis but is instead usually a derivative of peripheral venous system stasis, particularly the pelvic veins. As such, the utility of a vena cava filter is certainly worthy of consideration. One thing is clear: Continued reliance on left ventricular devices will continue to drive interest and attention toward supporting the right.

\section{Reference}

1. Potapoz E, Starck C, Falk V, Eulert-Grehn J-J. Mechanical circulatory support: technical tips for the implantation of a right ventricular assist device. $J$ Thorac Cardiovasc Surg Open. 2021;8:37-40.

\footnotetext{
From the Department of Cardiovascular and Thoracic Surgery, West Virginia Medicine, Morgantown, WVa.

Disclosures: The authors reported no conflicts of interest.

The Journal policy requires editors and reviewers to disclose conflicts of interest and to decline handling or reviewing manuscripts for which they may have a conflict of interest. The editors and reviewers of this article have no conflicts of interest.

Received for publication Oct 3, 2021; revisions received Oct 3, 2021; accepted for publication Oct 19, 2021; available ahead of print Nov 11, 2021.

Address for reprints: J. W. Awori Hayanga, MD, MPH, Department of Cardiovascular and Thoracic Surgery, West Virginia University, 1 Medical Center Dr, Morgantown, WV 26506 (E-mail: jeremiah.hayanga@wvumedicine.org).

JTCVS Open 2021;8:41

2666-2736

Copyright (c) 2021 The Author(s). Published by Elsevier Inc. on behalf of The American Association for Thoracic Surgery. This is an open access article under the CC BY-NC-ND license (http://creativecommons.org/licenses/by-nc-nd/4.0/).

https://doi.org/10.1016/j.xjon.2021.10.016
} 